\title{
The Intraneural Plexus of Fasciculi and Fibers in the Sciatic Nerve
}

\author{
JOHN CHARNLEY MCKINLEY
} MINNEAPOLIS

Reprinted from the Archives of Neurology and Psychiatry October, 1921, Vol. VI, pp. 377-399

Corxasabr, 1921

A gezicar Memical Associntion

Five Hendiso and Trikty-Five Nokth Dearnors Streat CHICAGO

\section{MOD}

M21 


\section{THE INTRANEURAL PLEXUS OF FASCICULI AND FIBERS IN THE SCIATIC NERVE*}

\section{JOHN CHARNLEY MCKINLEY}

MINNEAPOLIS

During the past fifteen years various writers have developed the conception of fiber tracts within peripheral nerves analogous to those in the spinal cord and brain. That is, in a given nerve, the fibers that supply a certain muscle or a certain area of the skin have been thought to be situated constantly within a definite region of the trunk of the nerve at a given level. Thus, the anatomist Bardeen, ${ }^{1}$ from his observations on the segmental distribution of the peripheral nerves of the lower extremity in the embryo and his dissections of nerve trunks in the adult, comes to the conclusion that, though nerves are made up of anastomosing bundles of fibers, the actual course of the fibers is for the most part a straight one from the plexus to the point where a peripheral branch is given off. Further, he thought that a given segmental level of the cord is represented by a certain area of the cross section of a nerve trunk if the nerve arises from more than one segment of the cord. A few years later, Stoffel, ${ }^{2}$ apparently without knowledge of Bardeen's observations, developed a similar idea of functional topography in peripheral nerves, basing his conclusions on gross dissection and a study of cross sections of nerves at different levels. $\mathrm{He}$ diverges from Bardeen in that he considers fasciculi simply as continuations of the peripheral branches of nerves and therefore thinks it possible grossly to recognize high up in a nerve trunk the exact fasciculi or groups of fasciculi which make up a given peripheral branch. He figures cross sections of nerve trunks showing the arrangement of the bundles according to the branches which he thinks they represent. With this idea in mind he sets down various rules of operative procedure to be followed in the case of nerve suture, transplantation and the like.

* A thesis submitted to the faculty of the graduate school of the University of Minnesota, in partial fulfilment of the requirements for the degree of Doctor of Philosophy in Nervous and Mental Diseases, 1921.

1. Bardeen, C. R.: Development and Variation of the Nerves and the Musculature of the Inferior Extremity and of the Neighboring Regions of the Trunk in Man, Am. J. Anat. 6:259, 1906.

2. Stoffel, A.: Beiträge zu einer rationellen Nervenchirurgie, München. med. Wchnschr. 60:175 (Jan.) 1913. Neues über das Wesen der Ischias und neue

ส Wege für die operative Behandlung des Leidens, München. med. Wchnschr.

60:1365 (June) 1913. Stoffel, A. und Vulpius, O.: Orthopädische Opera-

z tionslehre, Stuttgart, 1913. Stoffel, A.: Ueber die Behandlung verletzter Nerven

5 im Kriege, München. med. Wchnschr. 62:201 (Feb.) 1915. 


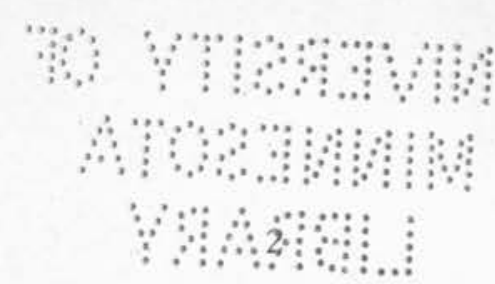

General interest in this field was lacking, however, until the great war centered the attention of physicians on nerve anatomy and physiology with the hope that nerve therapeutics would be furthered by such new facts as could be ascertained.

A new method investigating this problem was introduced during the period of the war by Marie. ${ }^{3}$ By faradic stimulation of nerves exposed at operation and noting the consequent muscular contraction, this writer ${ }^{4}$ reached essentially the same conclusions as Stoffel. Other workers ${ }^{5}$ have taken up and confirmed many of Marie's findings. The ideas of Stoffel, Marie and their supporters have received general recognition and are much quoted in important treatises on the diagnosis and treatment of nerve lesions. ${ }^{6}$

But this conception of traet systems within peripheral nerves, especially of fasciculi or groups of fasciculi representing peripheral branches of the nerves, has not gone unchallenged. Sherren ${ }^{7}$ states that:

Certainly a third of the (nerve) trunk, may be divided without producing motor or sensory change or one of transient nature only. I have on several occasions divided one third of the internal popliteal nerve without producing any paralysis, often no sensory change, occasionally a loss of power of appreciating light touches which returned in a few days.

But if the incision cuts into the nerve just above the point of origin of a branch the signs of complete division of that branch are produced. In certain situations also-for example, in the anterior primary division of the fifth cervical nerve-the nerve fibers are arranged in a well-defined order, and incomplete division of this nerve may entail complete division of those motor fibers which supply the spinati and the deltoid muscles. Again, in the trunk

3. Marie, P.: Des résultats fournis par l'électrisation directe des troncs nerveux dans la plaie opératoire chez les blessés atteints de traumatismes des nerfs, Bull. de l'Acad. de méd. 73:173 (Feb.) 1915.

4. Marie, P.; Meige, H., and Gosset, A.: Les localisations motrices dans les nerfs périphériques, Bull. de l'Acad. de méd, 74:798 (Dec.) 1915.

5. Putti, V.: Sulla topografia fascicolare dei nervi periferici e più specialmente dello sciatico popliteo esterno, Clin. chir. 24:1021, 1916. Benisty, Mme. A. (Translation by Buzzard, E. F.): Treatment and Repair of Nerve Lesions, University of London Press, London, 1918. Kraus, W. M., and Ingham, S. D.: Electrical Stimulation of Peripheral Nerves Exposed at Operation, J. A. M. A. 74:586 (Feb. 28) 1920. Peripheral Nerve Topography-Seventy-Seven Observations of Electrical Stimulation of Normal and Diseased Peripheral Nerves, Arch. Neurol. \& Psychiat. 4:259 (Sept.) 1920.

6. Tinel, J. (Translation by Joll, C, A.) : Nerve Wounds, William Wood \& Co., New York, 1918, U. S. Army Manual of Neuro-Surgery, Government Printing Office, Washington, 1919.

7. Sherren, J.: Injuries of Nerves and Their Treatment, William Wood \& Co, New York, 1907. 
of the great sciatic nerve, the external and internal popliteal nerves remain separate from their origin in the pelvis, hence incomplete division of the great sciatic may cause complete division of the external or internal-popliteal nerve.

Heinemann s has made dissections of the human median, ulnar and sciatic nerves, following the methods of Stoffel. ${ }^{2}$ He concludes that Stoffel's conception is entirely erroneous and misleading. The figures of his dissections show plainly numerous and irregular anastomoses and divisions of the bundles of these nerve trunks throughout their whole lengths.

Langley and Hashimoto, ${ }^{9}$ without reference to Stoffel's or Heinemann's work, have made dissections similar to theirs, using the sciatic trunk, the tibial and common peroneal nerves of man and of some of the domestic animals. They describe close plexuses along the course of these nerves and are unable to trace muscular branches proximally, as entities, for any great distance, though certain cutaneous branches remain separate for relatively long distances $(24 \mathrm{~cm}$. in the case of the N. cutaneous surae lateralis).

Dustin ${ }^{10}$ has made an extensive study of the median, ulnar and radial nerves. He studied them in a way similar to those of Heinemann, and Langley and Hashimoto. In addition he made cross-sections at centimeter intervals so that he could follow their fascicular topography at different levels more accurately than had been done in the past. Kraus and Ingham ${ }^{5}$ are the only writers on the subject who have referred to Dustin's work. They state that "the work is purely anatomical and, though of importance, led to no correlation with the functions of the fasciculi he describes." This is true but misleading, as can be seen from Dustin's article:

1. The arrangement of fasciculi varies considerably from nerve to nerve and from individual to individual.

2. The fascicular topography of the same nerve is continually modified by the exchange of numerous anastomoses between the various fasciculi.

From the above it becomes impossible to conceive of a functional systematization of nerves with fasciculi as its basis anatomically. However, one may admit that in every quadrant of a nerve (anterior, posterior, internal and external) such and such motor or sensory fibers are grouped by preference.

8. Heinemann, O.: Ueber Schussverletzungen der peripheren Nerven. Nebst anatomischen Untersuchungen über den inneren Bau der grossen Nervenstämme, Arch. f, klin. Chir. 108:107 (Aug.) 1916.

9. Langley, J. N., and Hashimoto, M.: On the Suture of Separate Nerve Bundles in a Nerve Trunk and on Internal Nerve Plexuses, J. Physiol. 51:318 (Sept.) 1917.

10. Dustin, A. P.: La fasciculation des Nerfs, Ambulance de "YOcean" 2:135 (July) 1918. 
One may not, however, subscribe to the exact ideas of Stoffel nor to the conclusions of P. Marie, Gosset and Meige on the existence of constant, distinct fasciculi definitely situated in the nerve trunks.

Results obtained by localized electric simulation are of value only for a given nerve at a given level. ${ }^{11}$

\section{FASCICULI IN THE HUMAN SCIATIC}

The right sciatic nerve of an adult human being was dissected and drawn natural size on a piece of plotting paper. Fig. 1 represents this plotting reduced to one-quarter its natural size. The nerve was cut into blocks, $1 \mathrm{~cm}$. in length; these were numbered serially and oriented spatially by stringing them on a thread which passed posteroanteriorly through the proximal end of each. They were imbedded in paraffin and cut serially, still keeping them oriented in space. For the most part sections were mounted at intervals of $3 \mathrm{~mm}$., though two blocks were mounted entire in order to trace the actual anastomoses and divisions of the fasciculi within a limited extent of the nerve (Fig. 6). The sections were stained with hematoxylin and orange $G$.

The numbers in Figure 1 refer to sections shown in Figures 2 to 5 . For example, in Figure 1, Numbers 10, 10, 10" indicate the levels of the sections diagrammed in Figure 2, number 10, Figure 4, number $10^{\prime}$ and Figure 5 , number $10^{\prime \prime}$, respectively. Figure 6 is drawn from sections taken from above the level at 10 to below that at 11 in Figure 1. Figures 2 to 5 are projectoscopic drawings. The fasciculi are shown in solid black and the connective tissue which cuts the fasciculi into groups is shown by lines.

Examination of Figures 2 and 3, which represent sections at centimeter intervals from the sacral plexus to the bifurcation of the sciatic, shows that no two sections have a similar fascicular topography. There is variation in the number, position and size of the bundles from section to section. Furthermore, the grouping of the fasciculi is variable from section to section in practically every case. The number of fasciculi is variable in the different sections, but in general they become larger and less numerous as the knee is approached, owing evidently to more fusion than splitting. If one then traces the sections out into the common peroneal and tibial it is seen that this fusion continues so that in the common peroneal (Fig. 5, section $5^{\prime \prime}$ ) there is a single bundle except for three small ones which are about to form the N. cutaneous surae lateralis and a small cutaneous ramus to the skin over the capitulum fibulae. In the tibial the reduction in number of the fasciculi is also marked; there are only three in the tibial trunk proper at the

11. Dustin's article was not available to me until my investigations had been completed (March, 1921). It was at once a disappointment and a satisfaction to note the close correspondence of our observations. 
level of Figure 4, Section $8^{\prime}$. If the sections are traced still farther, the fasciculi are seen to redivide into a considerable number of smaller bundles, apparently in preparation for the sending off of branches along the more distal course of the nerves.

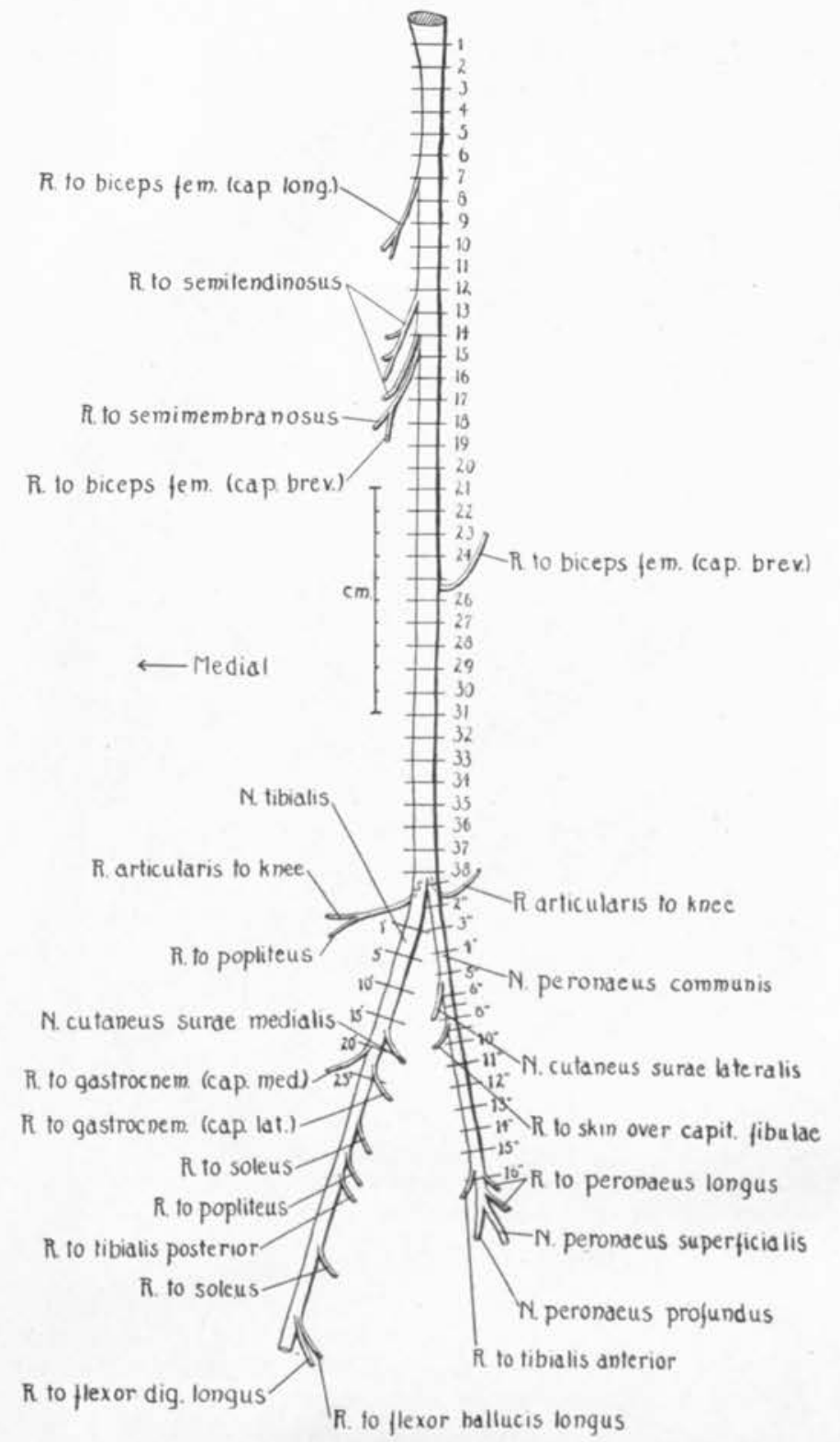

Fig. 1.-Diagram of the right sciatic nerve of an adult human being. The levels of the sections in Figures 2 to 6 are indicated by corresponding numbers in this figure, one-fourth natural size. 
The behavior of the fasciculi as they go to form the branches of the sciatic is of interest. While it is probably true that, the strands making up the common peroneal nerve do not fuse with any of the tibial nerve bundles and vice versa (we shall return to this in the next section of the article), it is possible to trace the respective groups only about half way up the sciatic trunk before we become uncertain as to
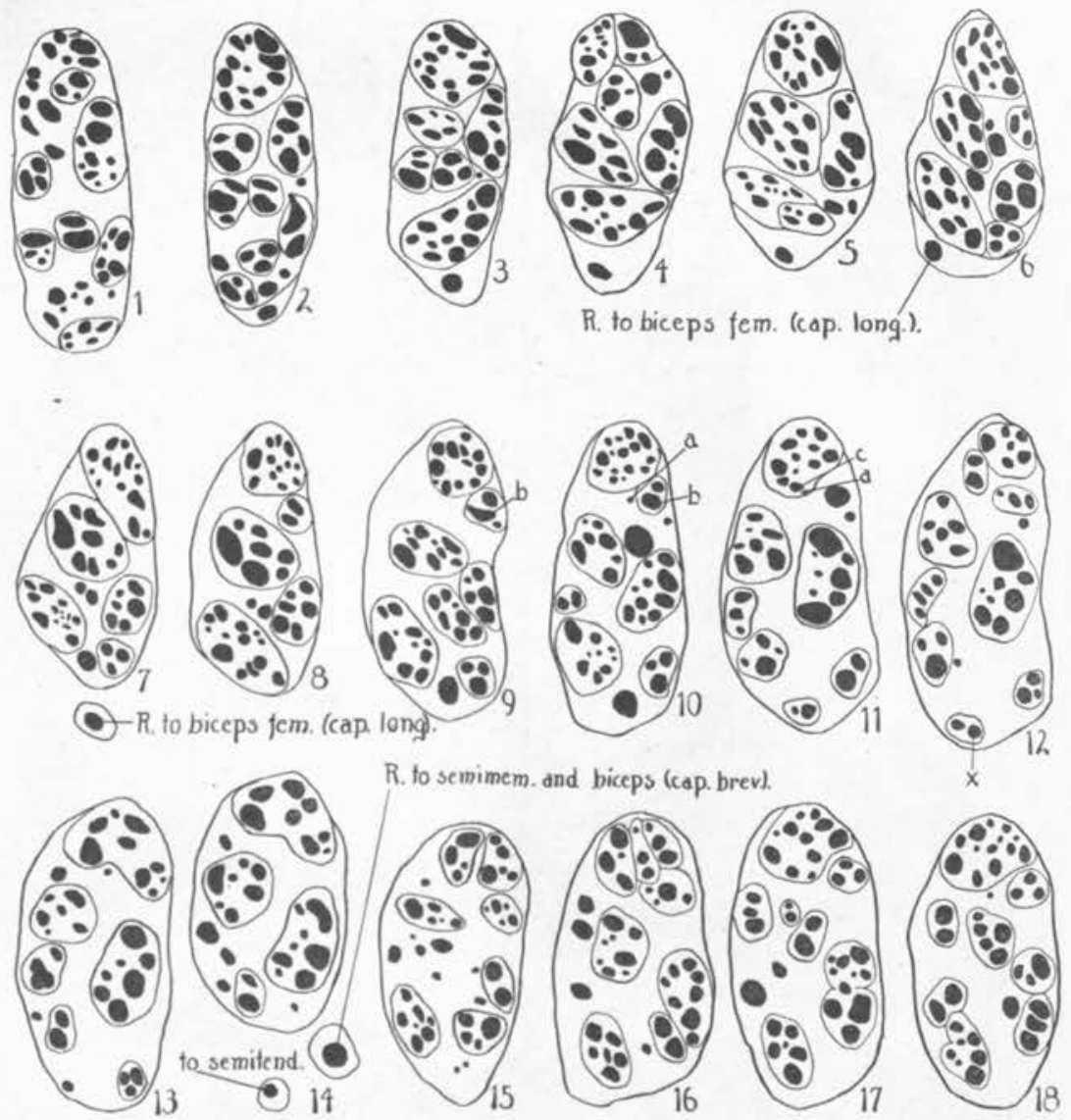

Fig. 2.-Sections at centimeter intervals. Fasciculi are shown in solid black. The connective tissue grouping of the bundles is indicated by the lines. Lateral is to the top of the page, posterior to the right; $\mathrm{X} 3$.

whether there is crossing over of the fibers. For example, in Figure 3 at number 38 the peroneal and tibial groups are widely separated; at number 19 or 20 the separation is questionable; and in Figure 2 it becomes practically impossible without sections at closer intervals to follow the two groups as separate entities. 
In the case of the fasciculi forming the collateral branches of the sciatic, the tibial and the common peroneal nerves, it will suffice to mention only those branches which are figured as they will serve to indicate the general principles of formation of collateral branches.

In Figure 2, section 7, the branch to the long head of the biceps femoris is seen to be leaving the sciatic. The fasciculus of this branch
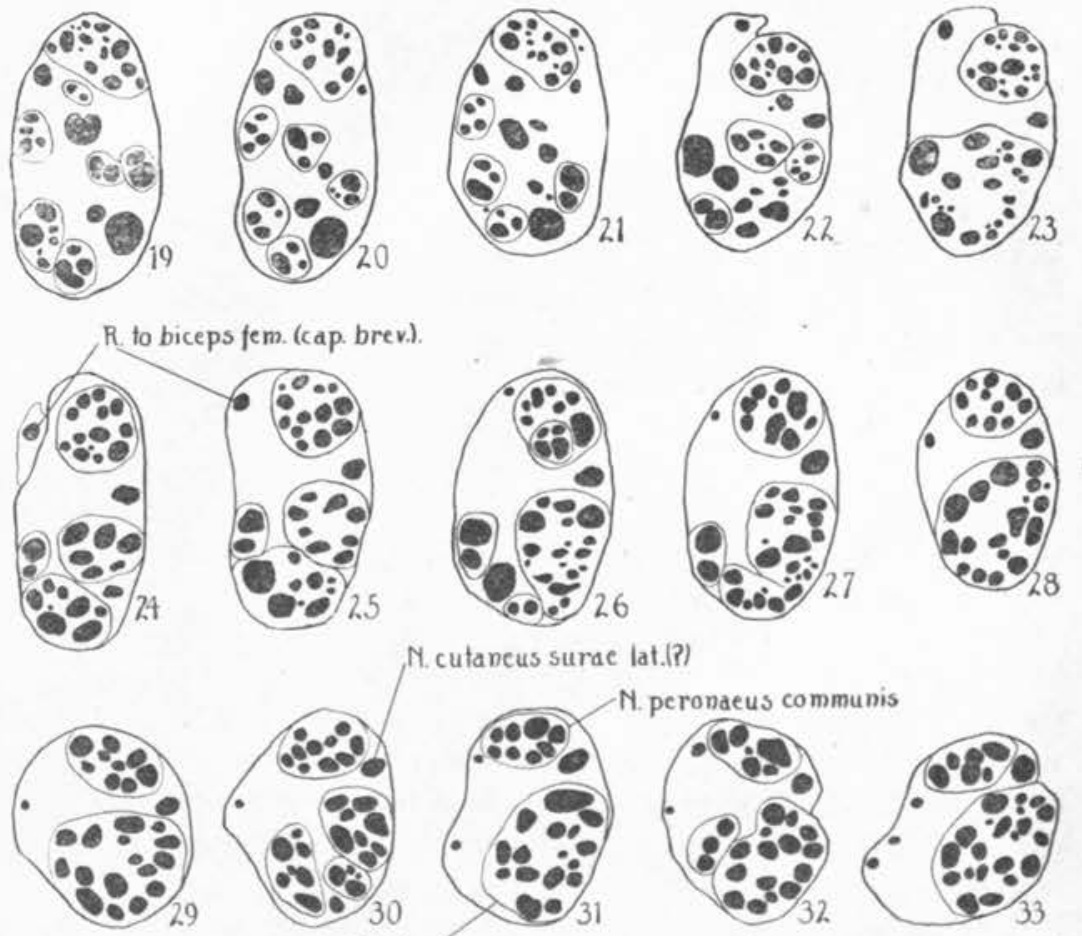

N. tibialis
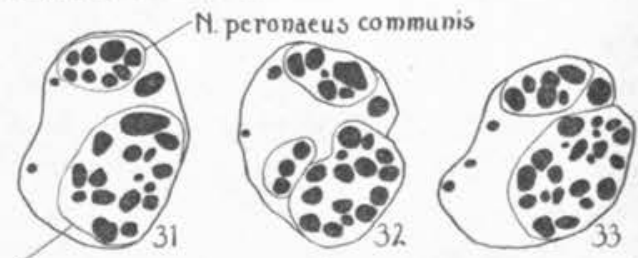

R. to skın over capit. fib.
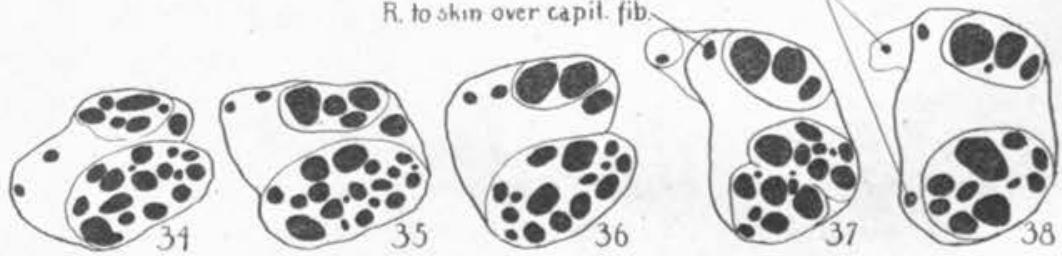

Fig. 3.-Continuation of Figure 2.

can be successfully traced to section 2 , or a distance of about $6 \mathrm{~cm}$. Between sections 12 and 13 a small branch is given off to the semitendinosus (Fig. 2, section $12 \mathrm{x}$ ) which is closely related to another branch to the semitendinosus which is seen leaving the sciatic in section 14. These two branches form fasciculi which fuse when traced proxi- 
mally into one bundle (section 10) which still farther proximally is again broken up (section 8 ). Thus the fasciculi to the semitendinosus are traceable as anatomically separate pathways for not over $5 \mathrm{~cm}$. along the nerve trunk from the point of departure of the branch. The other collateral branch leaving the sciatic trunk in section 14 runs to the semimembranosus and the short head of the biceps. The fasciculi to this branch can be traced proximally no farther than section 9 ( $5 \mathrm{~cm}$.). Just distal to section $25 \mathrm{a}$ branch is given off to the short head of the biceps, the fasciculus of which is traceable into section 22 (about $4 \mathrm{~cm}$.). It is conceivable that this bundle could be traced above this point if we had serial sections, but certainly for not more than 4 or 5 $\mathrm{cm}$. additional. Immediately below section 38 two small rami articulares to the knee joint leave the sciatic trunk, one on the tibial and one on the common peroneal side of the nerve. The one on the tibial side is almost immediately lost among the other tibial bundles, but the one on the peroneal side can be traced as high as section $26(12+\mathrm{cm}$.).

Three branches from the tibial trunk are shown in Figure 4. The sections are approximately $3 \mathrm{~mm}$. apart. The $\mathrm{N}$. cutaneous surae medialis is given off immediately below section $17^{\prime}$ (not shown in sections $16^{\prime}$ and $17^{\prime}$ in order to save space on the drawing) and can be traced proximally as a single fasciculus to section l' (but not to section 38 ), about $6 \mathrm{~cm}$. above the point of departure from the tibial. Just below the level of section $20^{\prime}$ a branch is given off to the medial head of the gastrocnemius (see section 13' for its identification and compare with Figure 1) the fasciculus of which can be traced to section $1^{\prime}$ but not to section 38. The extent of this fasciculus as a separate bundle is thus about $7 \mathrm{~cm}$. The branch to the lateral head of the gastrocnemius leaves the tibial trunk at the level of section $22^{\prime}$ (see section 11' for its identification) and can be traced also to section $1^{\prime}$, but not higher, a distance of about $7.5 \mathrm{~cm}$.

In Figure 5 are shown sections from the common peroneal trunk at the levels indicated in Figure 1 . The $\mathrm{N}$. cutaneus surae lateralis leaves the common peroneal just below section $5^{\prime \prime}$ and is traceable with certainty as a single fasciculus into section $3^{\prime \prime}$, though from the figures it is possible that this fasciculus may extend as high as section 22 , a distance of about $21 \mathrm{~cm}$. It is evident that these fibers are located within a definite area of the nerve, while it must be admitted that other fibers probably run along with them (Fig. 3 , section $30-\mathrm{N}$. cutaneous surae lateralis?). The branch to the skin over the head of the fibula leaves the common peroneal nerve near the level of section $8^{\prime \prime}$ - the fasciculi can be seen in section $7^{\prime \prime}$. This branch is traceable with fair certainty to section 32, a distance of $13 \mathrm{~cm}$. The branch to the tibalis anterior leaves the common peroneal about $0.75 \mathrm{~cm}$. below section $15^{\prime \prime}$ and 
cannot be identified in section $14^{\prime \prime}$ so that its fasciculus remains separate from the rest of the nerve for a distance of not over $2 \mathrm{~cm}$. Three small rami to the peroneus longus are seen to be leaving the peroneal trunk at and immediately below section $16^{\prime \prime}$. These branches are represented by three small fasciculi in section 16" which cannot be
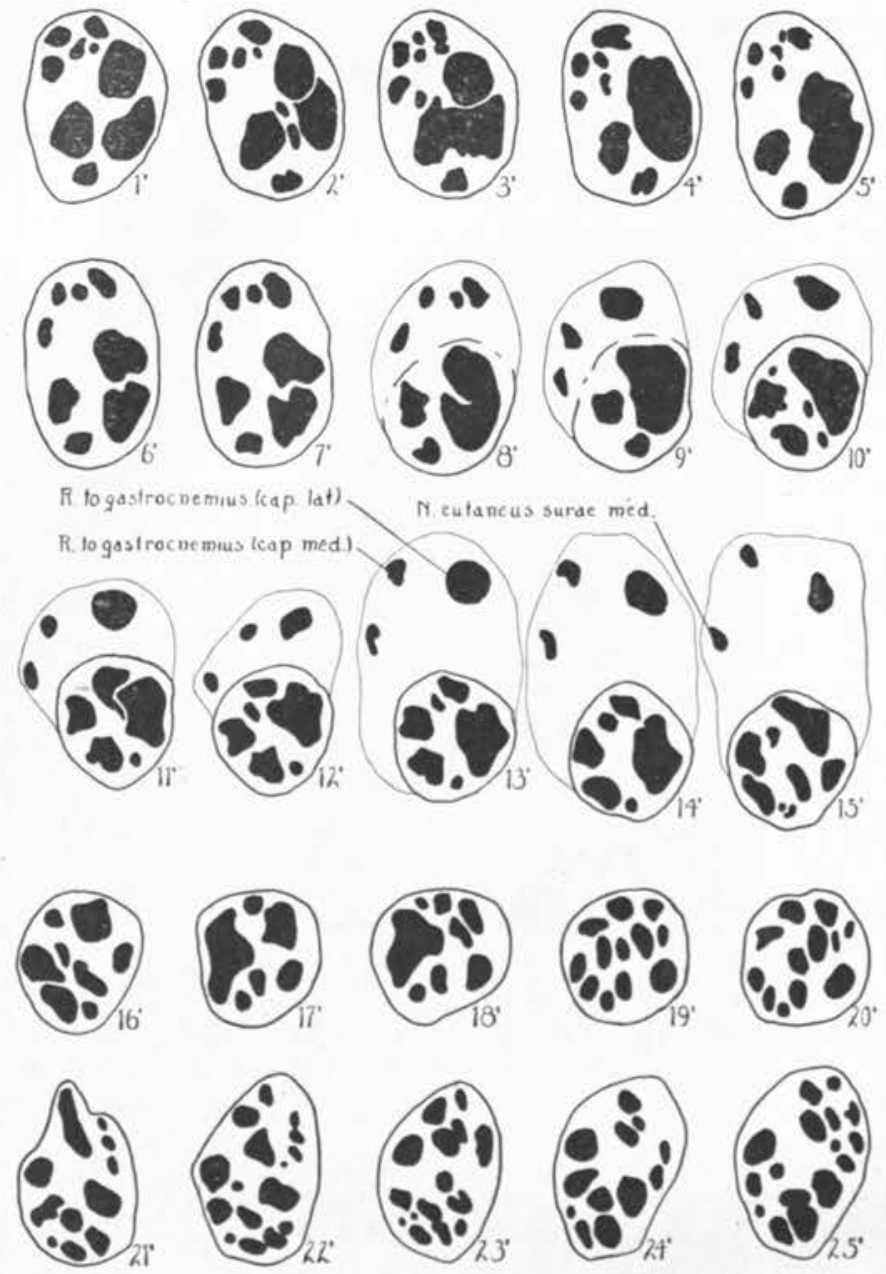

Fig. 4.-Sections at $3 \mathrm{~mm}$. intervals of the right tibial nerve. The numbers of the sections correspond to those in Figure 1. Fasciculi are shown in solid black. Lateral is to the top of the page, posterior to the right; X 4 .

identified above section $15^{\prime \prime}$, a distance of about $1.5 \mathrm{~cm}$. In this same section $\left(16^{\prime \prime}\right)$ we note that the common peroneal is dividing into its two terminal branches, the superficial and the deep peroneal nerves. The two corresponding groups of fasciculi apparently remain separate from one another up to sections $8^{\prime \prime}$ or $9^{\prime \prime}$, a distance of about $5 \mathrm{~cm}$. 
It also seemed worth while to determine accurately by serial sections, the exact amount of fusion and division of the fasciculi within a limited extent of the sciatic at a point where the sectional topography does not indicate a rapid shifting of the nerve fibers from one bundle to another. Two centimeter blocks, 10 and 11 (Fig. 1), were chosen for this purpose. Figure 6 is a graphic representation of the results of the study of these two blocks. The sections drawn were taken at sufficient intervals so that a number of anastomoses or divisions of the fasciculi have occurred between any successive two of them. Fasci-
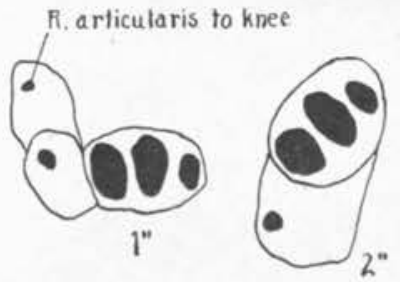

N. cutaneus surae lat.
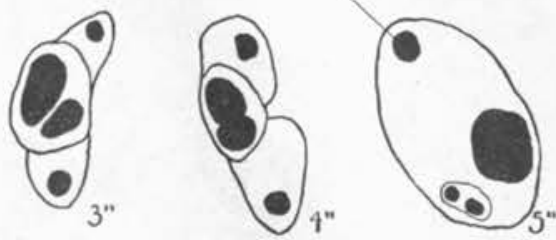

R. to skin over capit. fibulae
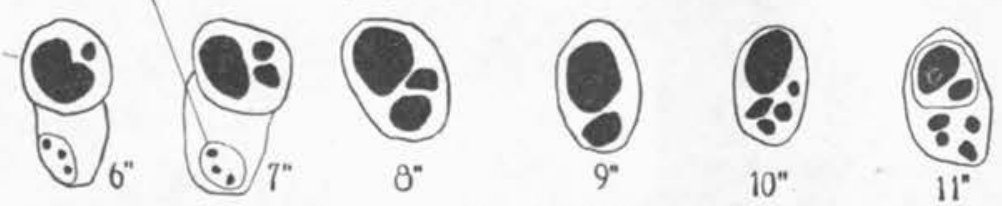

N. peronaeus superficialis.
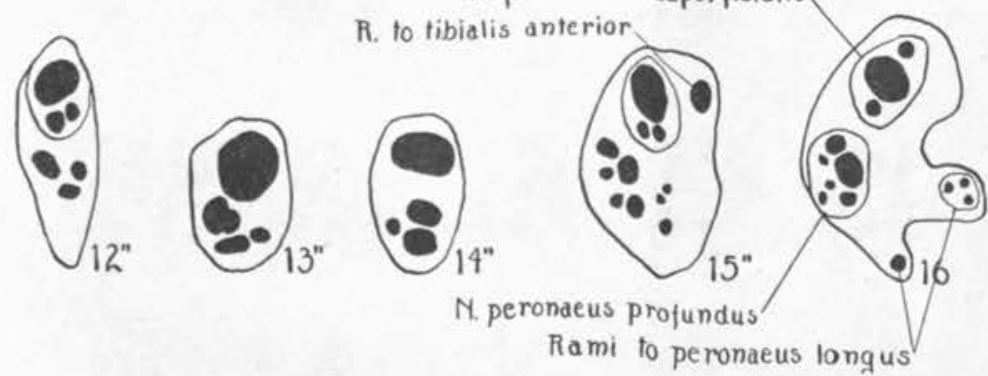

Fig. 5.-Sections of the right common peroneal nerve. The numbers of the sections correspond to those in Figure 1. Fasciculi are shown in solid black. The connective tissue grouping of the fasciculi is indicated by the lines. Lateral is to the top of the page, posterior to the right; $\mathrm{X} 4$.

culi which do not fuse or divide in the course of the nerve between any two of the sections shown are drawn in stipple; fasciculi which do divide or fuse are shown in solid black. Section 1 contains fortynine fasciculi and section 8 contains forty-one, a reduction of eight bundles within these two centimeters. This reduction would be most simply explained by assuming that eight fusions of the fasciculi had occurred in the region. However, we find that from section 1 to 
section 8 there are twenty-three fusions and fifteen divisions, a predominance of eight fusions. Thus, in this limited extent there is considerable passage of fibers from one bundle to another, though on superficial examination it would appear that the fascicular topography did not vary to any marked degree. Another point of interest is indicated in this drawing. The fasciculus marked "a" is an offspring of the one marked "b" (compare with Figure 2). Within these two
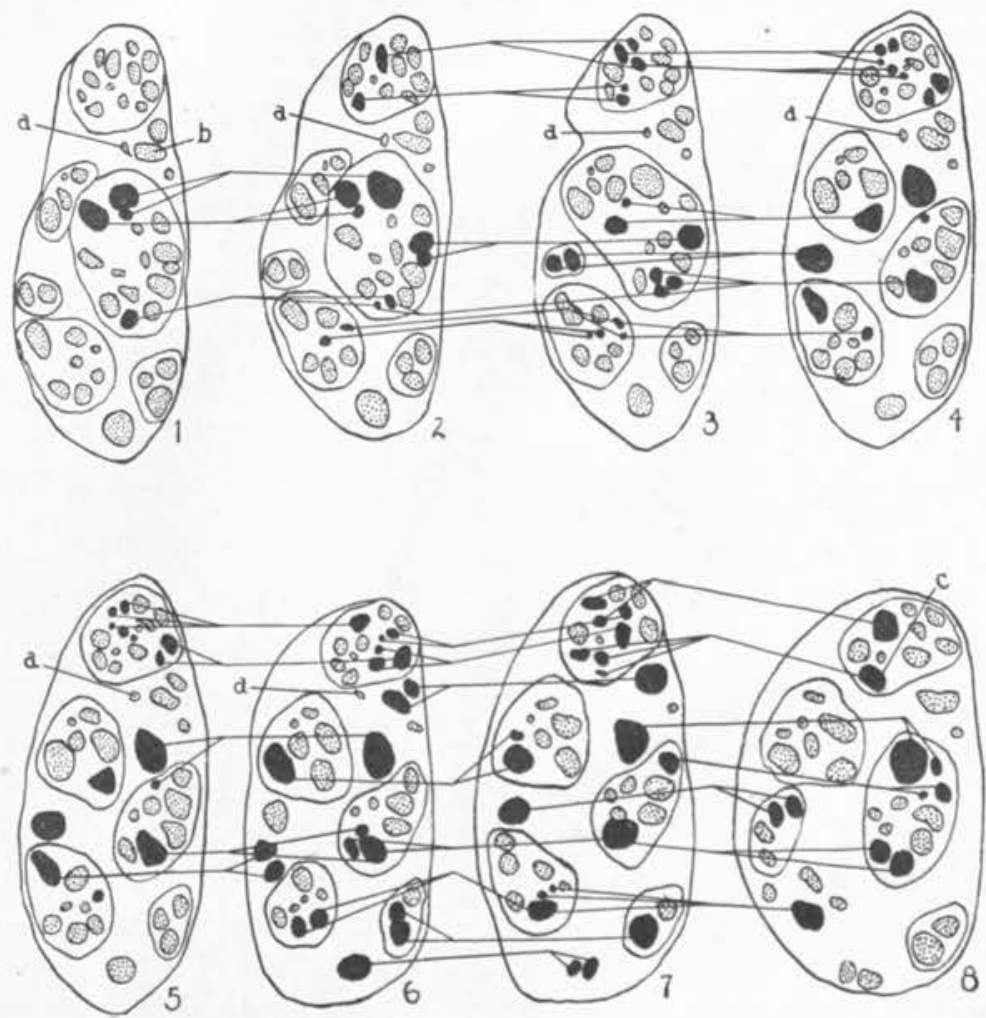

Fig. 6-Anastomoses and divisions of fasciculi in $2 \mathrm{~cm}$. of the sciatic trunk from above section 10 to below section 11 in Figure 1. Anastomosing or dividing fasciculi are shown in solid black; the others are stippled. Lateral is to the top of the page, posterior to the right; $\times 4$.

centimeters " $\mathrm{a}$ " moves from the more posterior portion of the nerve, crosses the midline and comes to lie in the more anterior portion, after which it is incorporated in the fasciculus "c". This shows that groups of fibers may quickly cross from one side of the nerve to the other without any marked change in the topographical picture, though as a rule the anastomoses appear to concern adjoining fasciculi. 
The foregoing findings may be summarized as follows:

1. The sciatic is made up of fasciculi which fuse and divide throughout the course of the nerve, forming a vast intraneural plexus.

2. Fusion predominates over division proceeding distally, so that proximally the sciatic is made up of a large number of relatively small fasciculi while in the more proximal portions of its two terminal branches the nerve is composed of relatively few large fasciculi. From about the level of the knee distally, the reverse holds true. The proximal part of the tibial and common peroneal is composed of few large fasciculi which soon split up into a large number of small ones as the more peripheral branches are formed.

3. There is continued crossing of fibers from one fasciculus to another, consequently opportunity for a complete change of functional topography throughout the course of the nerve (e.g., "a" in Fig. 6).

4. Fasciculi in the trunks of the common peroneal, tibial and sciatic nerves may be traced proximally from their respective points of departure for variable distances up the nerve trunks. Aside from the separation of the sciatic trunk into the tibial and common peroneal (which is probably complete), the bundles to the various collateral and terminal branches can be traced a maximum of $21 \mathrm{~cm}$., a minimum of $1 \mathrm{~cm}$. and an average of $6.5 \mathrm{~cm}$. before they are lost in the neightoring fasciculi.

THE COURSE OF DEGENERATED FIBERS IN PARTIALLY DIVIDED NERVES

In order to study the course of the fibers within the sciatic, the following method was undertaken on a number of dogs:

The nerve was bared under aseptic conditions between the ischial tuberosity and the greater trochanter of the femur and was partially divided with a very fine cataract knife so as to cut through various segments of the nerve in the different experiments. The dogs were killed after fourteen days and the sciatic nerves with their branches were stained according to the Marchi method. We could thus study the course of the fibers in a given segment of the nerve just as tracts in the spinal cord have been studied.12

Figures 7 and 8 graphically tabulate the results.

Figure 7 shows the degenerations obtained from division of the common peroneal at the level stated. In the figures the degenerated areas of the nerve are shown in stipple, while the normal regions are

12. In these experiments free use has been made of Ellenberger, W. u. Baum, H.: Anatomie des Hundes, Verlag von P. Parey, Berlin, 1891. Serial sections in the longitudinal plane were made to determine the presence or absence of degenerated fibers throughout these experiments. 


\begin{tabular}{|c|c|c|c|c|c|}
\hline & Exp. 1. & Exp. 2. & Exp. 3. & Exp. 4. & Exp. 5 . \\
\hline \multicolumn{6}{|l|}{ N. ischiadicus } \\
\hline R. to biceps femoris & & & & (2) & \\
\hline N. perondeus commun. & $00: 0^{\circ}$ & & & & \\
\hline $\begin{array}{l}\text { N. perondeus } \\
\text { superficialis }\end{array}$ & $\begin{array}{c}\text { Complete } \\
\text { Complo }\end{array}$ & $\begin{array}{l}\text { No } \\
\text { sections }\end{array}$ & 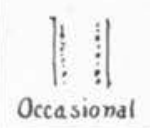 & $\begin{array}{l}\text { (2) } \\
\text { (1/4 } \\
0.7\end{array}$ & 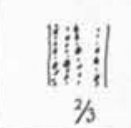 \\
\hline $\begin{array}{c}\text { N. peronaeus pro- } \\
\text { fundus below } \\
\text { rami to leg } \\
\text { muscles }\end{array}$ & $\begin{array}{c}\text { Complete } \\
\text { Com }\end{array}$ & $\underset{4 / 5}{4}$ & Occasional & $\begin{array}{c}\text { Occasional } \\
\vdots \\
0\end{array}$ & $\left|\begin{array}{cc}0 \\
\vdots \\
\vdots \\
1 / 2\end{array}\right|$ \\
\hline $\begin{array}{l}\text { R. to tibialis } \\
\text { anterior }\end{array}$ & $\begin{array}{c}\text { Complete } \\
\text { Ch }\end{array}$ & 10 & None & $\begin{array}{c}\mid \vdots \vdots \\
\text { Occasional } \\
\vdots\end{array} \mid$ & $\left|\begin{array}{c}0 \\
\vdots \\
\vdots \\
\vdots \\
\vdots \\
1 / 5\end{array}\right|$ \\
\hline $\begin{array}{l}R \text { to extensor } \\
\text { digitorum longus }\end{array}$ & $\begin{array}{c}0.31 \\
\text { Complete }\end{array}$ & \}$_{1 / 2}^{3}$ & None & 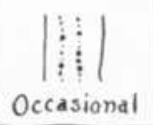 & $\mid$\begin{tabular}{c:c}
$1 / 4$ \\
\hdashline \\
\hdashline
\end{tabular} \\
\hline $\begin{array}{l}\text { R. to peronaeus } \\
\text { longus }\end{array}$ & Complete & $\begin{array}{c}1 / 3 \\
2 / 3\end{array}$ & $\mid$ & None & $\mid \begin{array}{l}1 \\
1 / 4\end{array}$ \\
\hline $\begin{array}{l}\text { R. to peronacus } \\
\text { tertius }\end{array}$ & Complete & $\left|\begin{array}{c}1 \\
\vdots \\
\vdots \\
1 / 3\end{array}\right|$ & None & $\begin{array}{c}\mid \\
\vdots \\
\text { Occasional }\end{array}$ & $\begin{array}{c}\text { No } \\
\text { sections }\end{array}$ \\
\hline $\begin{array}{l}\text { R. to peronacus } \\
\text { brevis }\end{array}$ & Complete & {$\left[\begin{array}{lll}1 / 2 \\
\hdashline\end{array}\right.$} & $\begin{array}{c}\left|\begin{array}{c}\mid \\
\vdots \\
1 \\
1 \\
1\end{array}\right| \\
\text { Occasional }\end{array}$ & $\begin{array}{c}\left|\begin{array}{c}\vdots \\
\vdots\end{array}\right| \\
\text { Occasional }\end{array}$ & $\begin{array}{l}\text { No } \\
\text { sections }\end{array}$ \\
\hline
\end{tabular}

Fig. 7.-Marchi degeneration following partial division of the common peroneal nerve. The branches under consideration are indicated in the column at the left. Degenerated fibers are shown in stipple; normal areas are left blank. "N. ischiadicus" indicates a section of the nerve just below the level of the lesion. "N. peronaeus communis" indicates a section of the common peroneal at the level of the knee. Anterior is to the left, lateral is to the bottom of the page for the sciatic and common peroneal sections. 


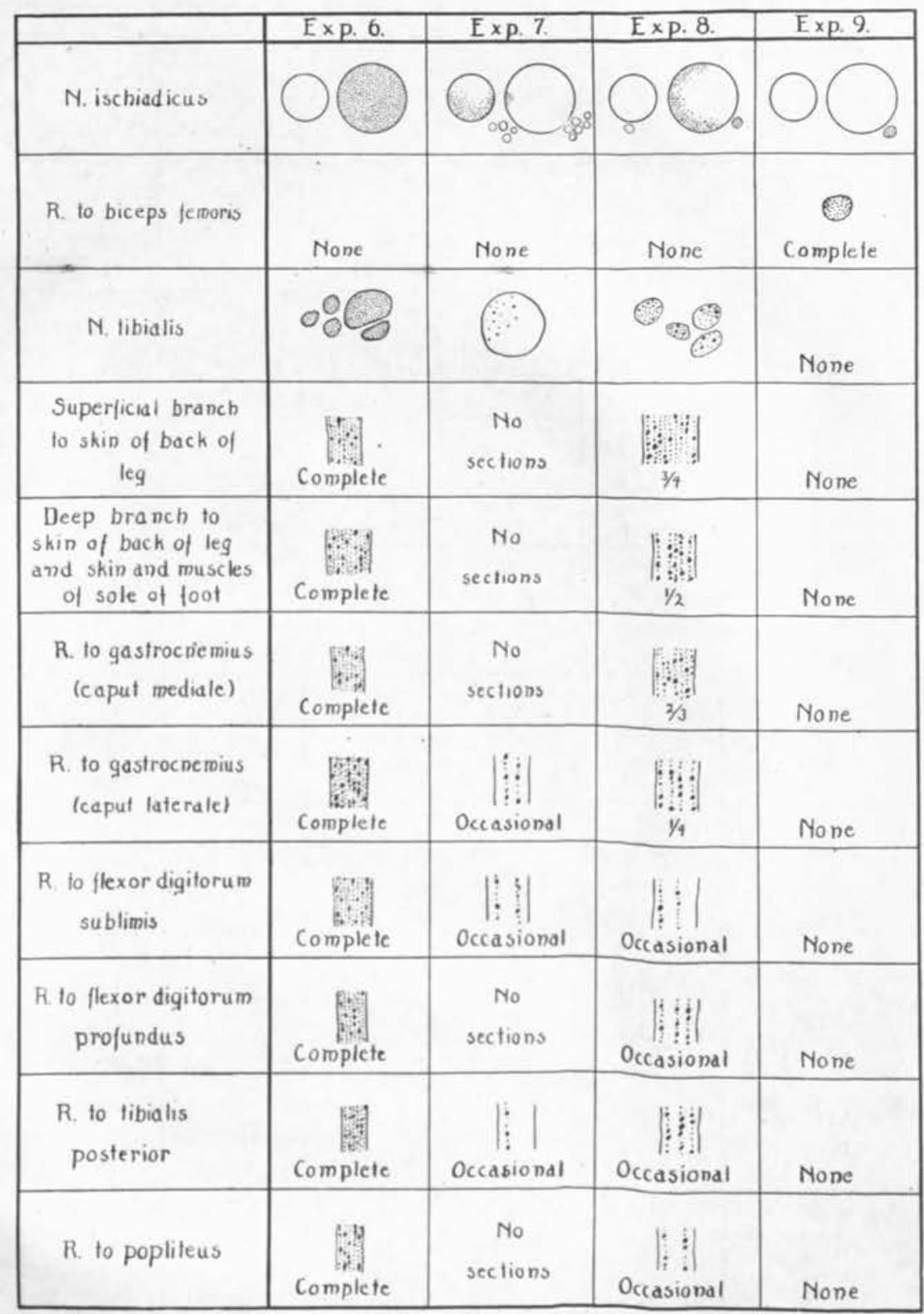

Fig. 8.-Marchi degeneration following partial section of the tibial nerve. The branches under consideration are indicated in the column at the left. Degenerated fibers are shown in stipple, normal areas are left blank. "N. ischiadicus" indicates a section of the sciatic trunk just below the level of the lesion. "N. tibialis" indicates a section of the tibial trunk at the level of the knee. Anterior is to the left, lateral is to the bottom of the page for the sciatic and tibial nerve sections. 
left blank. Thus, in Experiment 1 the whole common peroneal nerve was cut across, and we see a corresponding complete degeneration of all the fibers contained within it. Each of the branches of the common peroneal is likewise totally degenerated. No degeneration was found in the tibial nerve trunk nor in any of its branches.

In Experiment 2 approximately the lateral half of the common peroneal was divided, and we see a corresponding degeneration with the Marchi stain. The heading " $\mathrm{N}$. ischiadicus" indicates a section of the sciatic 1 or $2 \mathrm{~cm}$. below the level of the lesion. At the level of the knee the degenerated fibers are scattered throughout the whole diameter of the peroneal trunk. These diagrams may be checked by the photo-

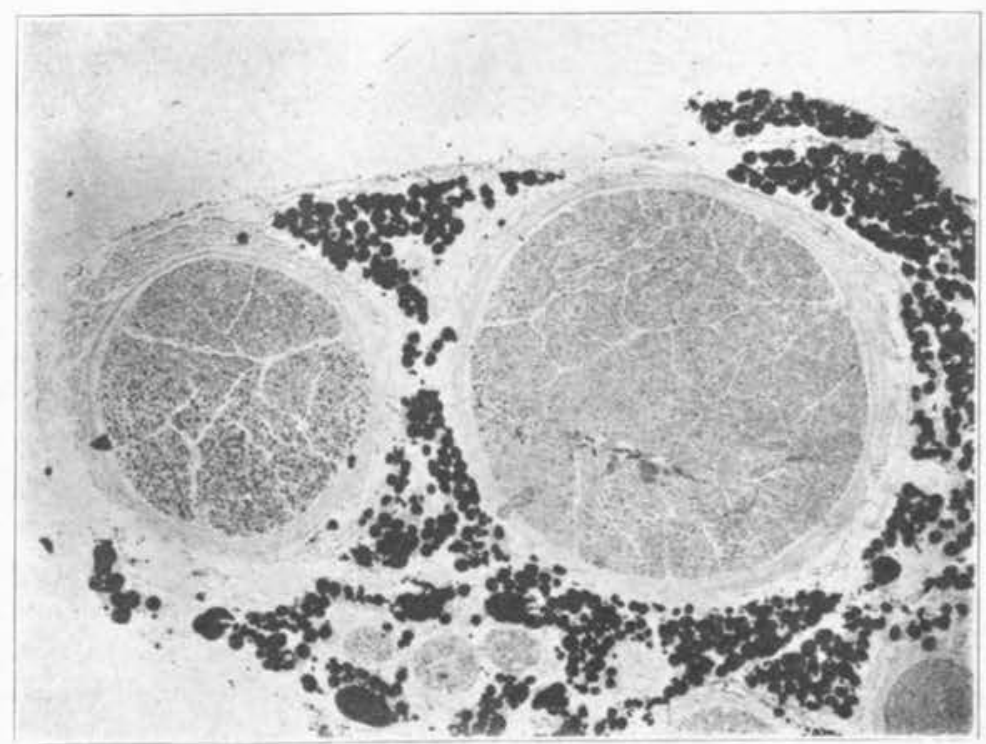

Fig. 9.-Photomicrograph of a Marchi section of the sciatic nerve just below the level of the lesion in Experiment 2. Posterior is to the right, lateral to the bottom of the figure; $\times 26$.

micrographs shown in Figures 9 and 10. Figure 9 corresponds to the drawing in Figure 7, Experiment 2, N. ischiadicus; Figure 10 corresponds to Experiment 2, N. peronaeus communis. There is degeneration in all sectioned branches of the common peroneal. About four fifths of the fibers in the N. peronaeus profundus below the point where the rami to the leg muscles are given off are degenerated, about two thirds of those in the branch to the peronaeus longus, about half the fibers to the extensor digitorum longus and the peronaeus brevis, and one third of those to the tibialis anterior and the peronaeus tertius are degenerated. Figure 11 is a photomicrograph of the branch to the 
peronaeus longus and may be used for comparison with the drawing of the degeneration of this branch shown in Experiment 2, N. to peronaeus longus (Fig. 7). In this same experiment there is slight degeneration of the anterior part of the tibial nerve which is traced out in Figure 8.

In Experiment 3 (Fig. 7) only a few fibers of the posterior side of the common peroneal were divided (see under N. ischiadicus). No degeneration is demonstrable in the branches to the biceps femoris, the tibialis anterior, the extensor digitorum longus and the peronaeus tertius. In sections of the $\mathrm{N}$. peronaeus communis the degenerated fibers are considerably scattered throughout the cross section of the nerve. Degeneration is demonstrable in about equal amounts in the $\mathrm{N}$. peronaeus superficialis, the N. peronaeus profundus below the rami to the leg muscles, the ramus to the peronaeus longus and to the peronaeus brevis.

The common peroneal in Experiment 4 shows compact degeneration in the anterior part and a few scattered degenerated fibers along the lateral side of the nerve. Also, a small fasciculus of the sciatic accompanying the common peroneal along its anteromedial side is completely degenerated. The branch to the biceps femoris is completely degenerated and is undoubtedly represented by the small fasciculus just mentioned. The N. peronaeus superficialis is about one quarter degenerated; there is no degeneration in the branch to the peronaeus longus and occasional degenerated fibers are found in each of the other rami studied.

In Experiment 5 the lateral third of the cross section of the common peroneal is degenerated, together with a small accompanying fasciculus which is completely degenerated. No completely degenerated branches are seen in this nerve so it must be assumed either that some branch (probably to the biceps femoris) has been lost in the dissection or that this fasciculus has fused and been incorporated again with the common peroneal. From a study of other sections in this series it is most probable that the former is the correct explanation. The N. peronaeus superficialis is about two thirds degenerated, the N. peronaeus profundus below the points of emission of the branches to the leg muscles about one half degenerated, the branches to the extensor digitorum longus and peronaeus longus each about one quarter, and the branch to the tibialis anterior about one fifth degenerated. No sections of the branches to the peronaeus tertius and brevis are available because of difficulty in dissection.

Figure 8 shows results of total and partial divisions of the tibial trunk. The caption "N. ischiadicus" again indicates a section of the sciatic trunk taken just below the level of the lesion. In Experiment 6 
the tibial has been divided completely. We find correspondingly complete degeneration of the tibial trunk and all its branches. There is no demonstrable degeneration in the peroneal division nor in any of its branches.

Experiment 7 is from the same nerve that is shown in Experiment 2 , but here the tibial degeneration is considered. We find that the small group of degenerated fibers at the anterior margin of the tibial division at the level of the lesion is scattered over at least the anterior

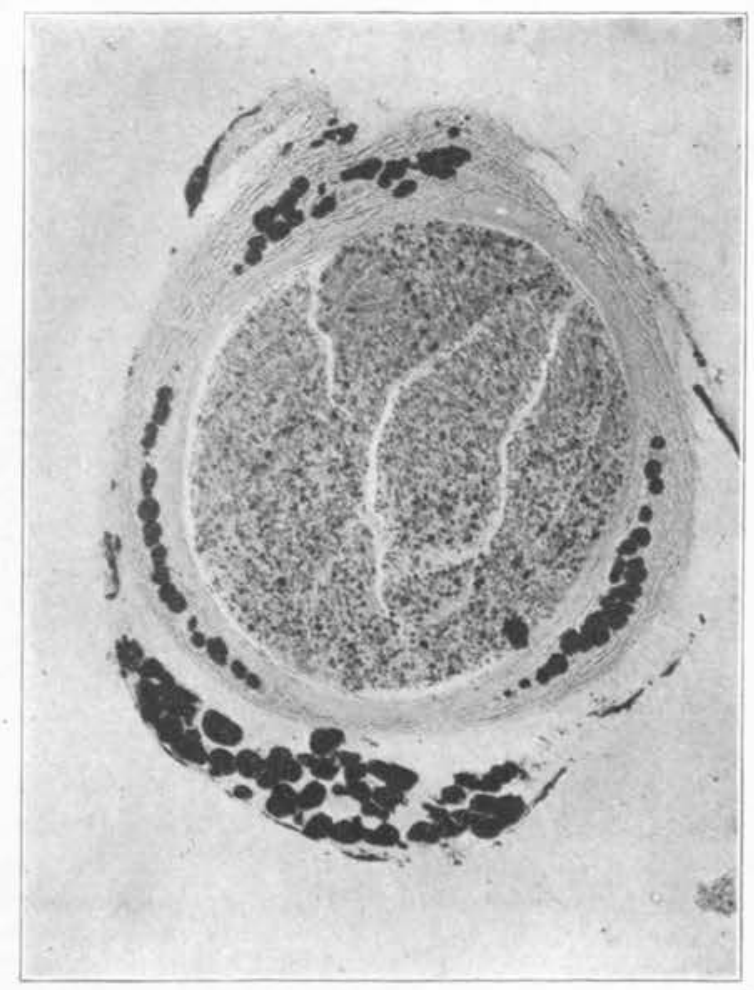

Fig. 10.-Photomicrograph of a Marchi section of the common peroneal nerve at the level of the knee in Experiment 2. Posterior is to the right, lateral to the bottom of the figure; $\mathrm{X} 46$.

half of the tibial trunk when sectioned at the level of the knee. Through some error sections of only three branches of the tibial are available in this experiment. However, all three of these rami show degenerated fibers.

In Experiment 8 the tibial trunk was divided along its lateral. anterior and medial margins (Experiment 8, N. ischiadicus). A small fasciculus accompanying the tibial side of the sciatic was also completely 
divided, and we are unable to trace this fasciculus into its terminal branch. The explanation in this case is the same as that already given for an analogous finding in Experiment 5. We see in this experiment (8) that at the knee level the tibial nerve is partially degenerated throughout its whole cross section. Also there is degeneration in every branch of this tibial nerve though most marked in the superficial branch to the skin of the back of the leg, in the ramus to the gastrocnemius and in the deep branch of the skin of the back of the leg and the skin and muscles of the sole of the foot.

In Experiment 9 only a small fasciculus was divided. The only branch of the sciatic found degenerated was a small one to the biceps femoris.

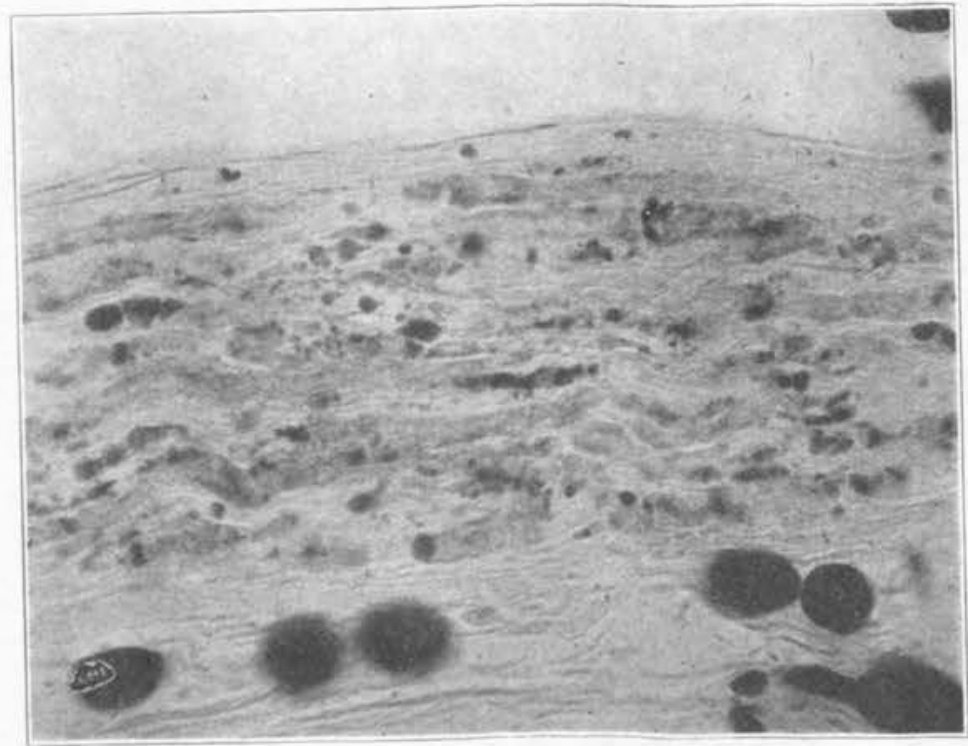

Fig. 11.-Photomicrograph of a longitudinal section of the nerve to the peronaeus longus in Experiment 2. The figure shows the typical appearance of degenerating myelin sheaths in longitudinal section when stained according to Marchi's method. About two-thirds of the fibers are degenerating; X 300 .

These experiments show that in the dog the tibial and common peroneal are completely separate from one another at least as high as the level of the ischial tuberosity and the greater trochanter of the femur. Also, partial division of the common peroneal or tibial gives regularly a degeneration which spreads out over most of the cross section of the nerve in its course down the sciatic trunk and is demonstrable in all of the peripheral branches if more than a very small area is divided. The fasciculi to the hamstring muscles are given off for the most 
part above the level at which these experiments were performed though occasionally a small fasciculus to the biceps femoris is seen coursing along with, but remaining separate from, the sciatic trunk for a short distance.

It is regrettable that the foregoing observations are so few and that they have been made on the dog, in which the tibial and common peroneal divisions consist each of a single bundle. Probably more satisfactory results would have been obtained had the goat been used, whose sciatic morphologically more closely resembles that of man and in which partial division of the nerve would have been simpler because of numerous fasciculi more or less visible to the naked eye (Langley and Hashimoto ${ }^{2}$ ).

ELECTRIC STIMULATION OF THE SCIATIC TRUNK IN THE DOG

A single experiment was done. In an anesthetized dog, the tendons around the ankle were dissected out and each connected by means of a string to its respective lever playing on a drum of smoked paper. The sciatic was isolated between the ischial tuberosity and the greater

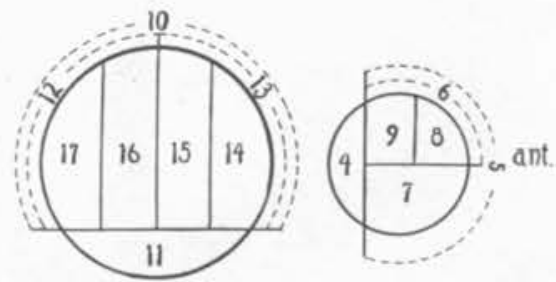

lat.

Fig. 12,-Diagram of the segments into which the sciatic nerve was split in the electric stimulation experiment. The numbers of the segments correspond to the tracing numbers in Figures 13 and 14; for example, when segment 4 (above) was stimulated, the record of the muscles which contracted is that in Figure 13 , tracing No. 4 .

trochanter of the femur, from 3 to $4 \mathrm{~cm}$. below the sacral plexus, was cut across and stimulated by means of an ordinary induction coil with small electrodes. The current used was the minimal to produce contraction of the muscles. In Figure 13, No. 1, is shown the tracing obtained on passing a current through the whole cross section of the nerve. All the muscles of the leg contracted.

With a fine cataract knife the nerve was then split for about 1.5 $\mathrm{cm}$. into its two divisions which were grossly visible: the common peroneal and the tibial. The first was then stimulated. The tracing obtained is shown in Figure 13, No. 2. The muscles supplied by the common peroneal contracted while those supplied by the tibial did not. Then the tibial was stimulated. The four tibial muscles contracted; the peroneal group did not. 
Next the common peroneal division was split longitudinally for about $1.5 \mathrm{~cm}$. into a number of segments as diagrammed in Figure 12 . When segment No. 4 was stimulated all the muscles of the peroneal group contracted; those supplied by the tibial did not (Fig. 13, No. 4). When the remaining portion of the common peroneal was stimulated (Fig. 12, No. 5) all the muscles of the peroneal group again gave a curve, while those of the tibial remained unaffected (Fig, 13, No. 5). The same was true for stimulation of all the other segments into which the common peroneal nerve was divided. This is easily seen by com-

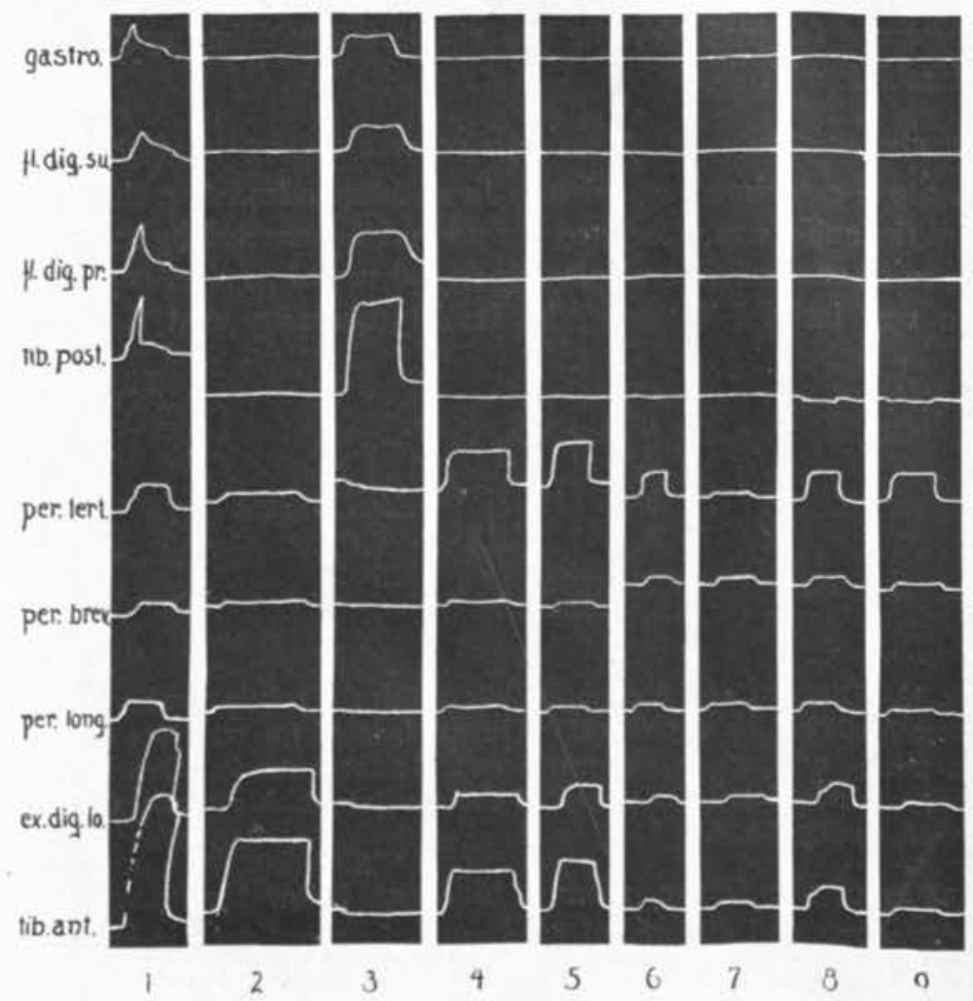

Fig. 13.-Tracings of the muscle contractions in the electric stimulation experiment.

paring the segment number in Figure 12 with the corresponding tracing in Figure 13.

The tibial division was treated in the same way. Here also the tracing number in Figure 14 corresponds to the segment number in Figure 12, which shows diagrammatically the approximate segments into which the tibial was split and then stimulated. In no instance was there contraction of the muscles supplied by the common peroneal. 
In every case, except in the stimulation of segments 11 and 14 , there was contraction of all four of the muscles of the tibial group from which tracings were obtained. On stimulation of segments 11 and 14 only the flexor digitorum profundus and the tibialis posterior contracted

We repeat that the current used was the minimal to produce muscl= contraction in order to avoid overflow.

This experiment indicates that in the sciatic of the dog at the level between the ischial tuberosity and the greater trochanter of the femur there is little grouping of the motor fibers into functional groups aside from the separation of the nerve into its two main divisions. The

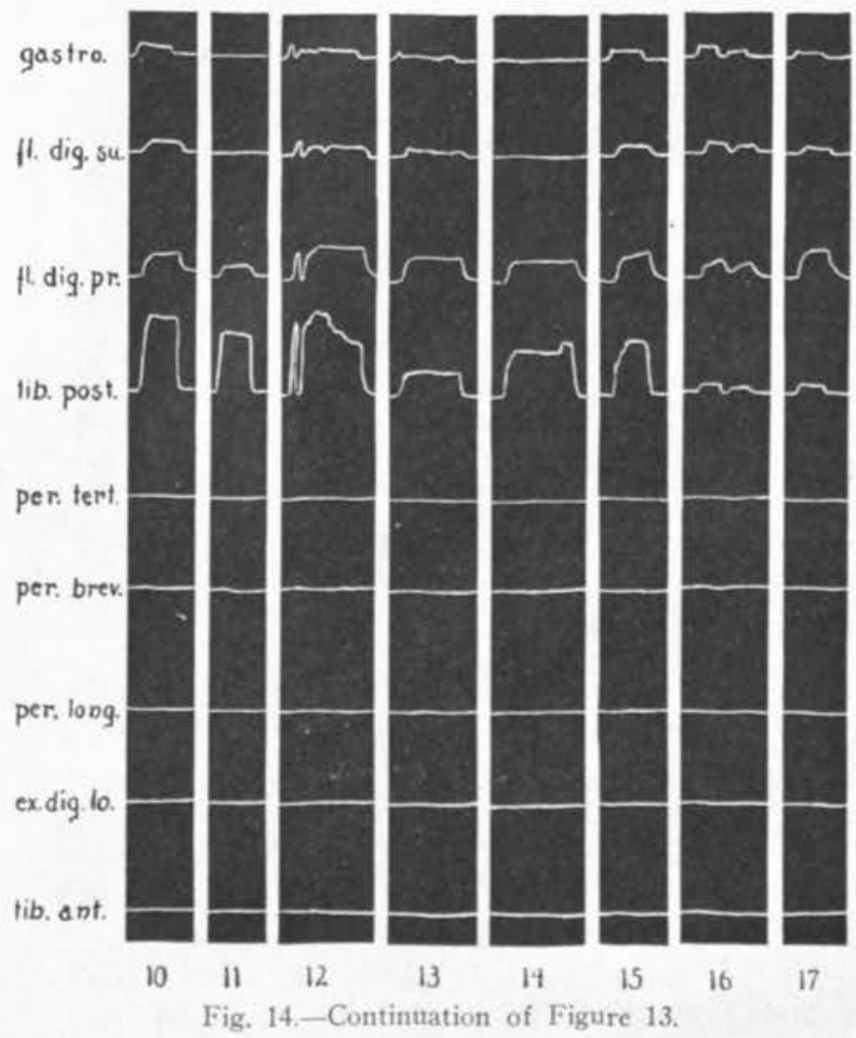

observations would have been more satisfactory if they had been carried out on a species whose sciatic is made up of a number of grossly visible fasciculi, as in the human being.

\section{DISCUSSION}

It has been shown in the foregoing that the tibial and common peroneal divisions of the human sciatic nerve should be considered as vast plexuses of nerve fibers from the sacral plexus to at least the 
distal part of the proximal third of the leg (well into the common peroneal and tibial trunks proper). This continuous exchange of fibers among the various fasciculi making up the nerve can mean only a continuous modification of the functional topography of the nerve throughout its length and definitely negatives the conception of Stoffel, Marie, ${ }^{3}$ and Kraus and Ingham,,$^{5}$ who would have us think of fasciculi in terms of peripheral branches. The only true functional localization in the sciatic, aside from separation into the tibial and common peroneal divisions, is that seen just above the points of departure of branches, since the fasciculi to the branches may be traced along the nerve trunk for an average distance of $6.5 \mathrm{~cm}$. (maximum $21 \mathrm{~cm}$., minimum $1 \mathrm{~cm}$.) before they are lost among neighboring bundles of nerve fibers.

In conformity with this we find, in the dog, that partial division of the sciatic between the ischial tuberosity and the greater trochanter of the femur shows complete separation of the nerve into its tibial and common peroneal divisions, but that partial division of either one of these two causes degeneration, not in single branches but in many of the respective branches of each of them. Hence, there must be very definite mixing of the nerve fibers throughout their course from the sacral plexus and the tibial and common peroneal nerves before peripheral branches are given off.

Electrical stimulation of various sections of the sciatic in the dog at the before mentioned level provokes contraction in all the muscles supplied by either the tibial or common peroneal, depending on which one is stimulated, and not in one or two of the muscles (exception noted in the foregoing).

Thus, in the light of this investigation and that of Dustin, ${ }^{10}$ it is impossible to conceive of any functional significance of fasciculi in peripheral nerves in the sense that "the course (of motor fasciculi) is a straight one from the point where the nerve has been made up by its contributing segments to the point of offset of the fasciculi as a branch"-Kraus and Ingham. ${ }^{5}$

In case of a transverse lesion of a nerve it is customary to operate as soon as one is convinced that there is no infection in the field of operation and no evidence of regeneration of the nerve-U. S. Army Manual. ${ }^{6}$ The operation then consists in resecting the scar tissue, the neuroma of the central stump and the glioma of the peripheral stump, until the normal nerve fasciculi in the one and the atrophied bundles of the other are distinctly evident. In the average operation, two or three or more centimeters of the nerve must be resected. Then it is advised to suture the divided ends without torsion in as nearly their normal anatomic relationships as possible. Marie says: "It is indispensable that in their sutures, the surgeons appose as exactly as pos- 
sible the sectioned ends of the various divided nerve fasciculi of the superior end with the same fasciculi of the inferior end." The impossibility of following to the letter any such procedure is at once apparent. Reference to Figure 6 shows that within $2 \mathrm{~cm}$. of the length of the sciatic trunk there are twenty-three fusions and fifteen divisions of the various bundles at this point and a reduction of eight fasciculi. Thus, after resection of the glioma and neuroma, the fasciculi in the proximal stump cannot correspond to those in the peripheral stump. This, however, does not mean that we cannot support the point of view of a minimum disturbance of the nerve topography in the way of torsion.

As Dustin ${ }^{10}$ points out, success of the suture of a nerve depends to a decided extent on the number of fasciculi in the nerve at the point at which it has been divided. If the area involved is where the nerve consists of many bundles, the growth of fibrous connective tissue from the perineurium between the two stumps is much more likely, apposition of normal fasciculi in the proximal stump to those in the peripheral stump becomes much more a matter of chance, and the regenerating axons are much more likely to go astray than if the section has occurred through a "nodal zone" (Dustin) where the fasciculi are few and relatively large, and where there is a minimum amount of connective tissue within the nerve proper. Though no statistics are available, one can deduce from the foregoing that, other things being equal, the prognosis of a sciatic lesion producing complete anatomic interruption is better in direct proportion as the lesion approaches the level of the knee where the fasciculi are few and large.

Again, on the basis of anatomic considerations, it is evident that partial division of the sciatic nerve just above the point of departure of a peripheral branch would be more likely to give symptoms of division of the branch than if the lesion were located higher up; in other words, there is localization of function anatomically for the various branches for only a few centimeters proximal to the level at which they leave the nerve. Hence, partial division of the nerve trunk would probably be more serious as regards a particular branch in direct proportion as the level of the lesion approaches the point of departure of the branch. Sherren " has already noted this principle as a clinical fact without explaining the underlying reasons for it.

It is a pleasure to acknowledge my indebtedness to my advisor. Dr. Arthur S. Hamilton, whose interest and example have been a constant source of stimulation throughout this work. 